\title{
Breast cancer in a male-to-female transsexual patient with a BRCA2 mutation
}

\author{
Vinciane Corman1,*, Iulia Potorac1,*, Florence Manto², Sarah Dassy3, Karin Segers4, \\ Albert Thiry ${ }^{5}$, Vincent Bours ${ }^{4}$, Adrian F Daly¹ and Albert Beckers ${ }^{1}$ \\ 1Department of Endocrinology, Centre Hospitalier Universitaire de Liege, Université de Liège, Liège, Belgium \\ ${ }^{2}$ Faculty of Medicine, Université de Liège, Liège, Belgium \\ 3Department of Oncology, St Nikolaus-Hospital, Eupen, Belgium \\ ${ }^{4}$ Department of Human Genetics, Centre Hospitalier Universitaire de Liege, Université de Liège, Liège, Belgium \\ ${ }^{5}$ Department of Anatomo-pathology, Centre Hospitalier Universitaire de Liège, Université de Liège, Liège, Belgium \\ $*$ ( V C and I P contributed equally to this work)
}

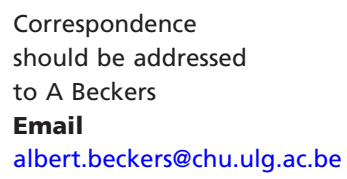

\begin{abstract}
Breast cancer is rare in male patients. Certain predisposing factors, be they genetic (e.g., BRCA2 gene mutations) or hormonal (imbalance between estrogen and androgen levels), have been implicated in male breast cancer pathophysiology. Male-to-female (MtF) transsexualism is a condition that generally involves cross-sex hormone therapy. Anti-androgens and estrogens are used to mimic the female hormonal environment and induce the cross-sex secondary characteristics. In certain situations, the change in the hormonal milieu can be disadvantageous and favor the development of hormonedependent pathologies, such as cancer. We report a case of a MtF transgender patient who developed breast cancer after 7 years of cross-sex hormonal therapy. The patient was found to be $B R C A 2$ positive, and suffered recurrent disease. The patient was unaware of being a member of an established BRCA2 mutation-positive kindred. This represents the first case of a $B R C A 2$ mutation predisposing to breast cancer in a MtF transgender patient.
\end{abstract}

\author{
Key Words \\ - breast cancer \\ transgender \\ - BRCA2 \\ - estrogen
}

\section{Introduction}

Transsexualism occurs with an estimated frequency of 1 in 11,900-12,900 males and 1 in 30,400-33,800 females (van Kesteren et al. 1996, De Cuypere et al. 2007). Maleto-female $(\mathrm{MtF})$ reassignments occur more frequently in middle-aged patients (van Kesteren et al. 1996). In $\mathrm{MtF}$ patients, development of female secondary sexual characteristics requires hormonal treatment with anti-androgens and estrogens. The doses of estrogens typically used in MtF patients are higher than those administered as substitutive therapy in hypogonadal women, and treatment in MtF patients is usually continued beyond the typical age of female menopause (Gooren et al. 2008).

With the exception of certain skin cancers, breast cancer is the most frequently diagnosed neoplasm in women, accounting for nearly $29 \%$ of all cancers. It ranks second in cancer mortality after lung cancer (American Cancer Society 2015). Male breast cancer represents only $1 \%$ in all cases of breast cancer in the US (American Cancer Society 2015) and <1\% of all male cancers (American Cancer Society 2015). At diagnosis, male breast cancer patients are, on average, 4 years older 
than women with breast cancer (64.8 vs 60.9 years) (Hill et al. 2005).

Among the genetic modifications that predispose to breast cancer, the primary contributors are the BRCA gene family. BRCA1 and BRCA2 are tumor suppressor genes (Miki et al. 1994, Wooster et al. 1995). Mutations in BRCA1 and BRCA2 account for $5-10 \%$ of cases of female breast cancer and $5-20 \%$ of male breast cancer (American Cancer Society 2015). The transmission of these mutations is autosomal dominant. Women in the general population have a $7 \%$ risk of developing breast cancer by the age of 70 , whereas the risks of BRCA1 or BRCA2 mutation carriers are around 60\% and 55\%, respectively (Mavaddat et al. 2013). The risk of a male BRCA2 mutation carrier of developing breast cancer is more than 80 times higher than that of the general male population, with a $2.8-7.1 \%$ chance by the age of 70, rising to $6.9-8.4 \%$ by the age of 80 (Thompson \& Easton 2001, Evans et al. 2010).

In this study, we describe what is, to our knowledge, the first documented case of breast cancer in a $\mathrm{MtF}$ transgender patient with a pathogenic BRCA2 mutation. We also review the available literature on related issues, as well as the pathogenesis of breast cancer in specific circumstances.

\section{Case report}

A 46-year-old biologically male patient who was seeking MtF transition was referred to a specialized endocrinologist. He had been diagnosed with sexual identity dysphoria and transsexualism 8 years previously. Before starting hormone therapy, the patient weighed $92 \mathrm{~kg}$, had a height of $1.82 \mathrm{~m}$, and had a normal physical examination. His medical history was unremarkable except for statin-treated hypercholesterolemia and he smoked five cigarettes daily. His family history revealed type 2 diabetes and prostate cancer in his father. The patient had fathered two children, both without significant health problems. General hematology and biochemistry results (glucose, liver, and renal function tests, blood count, lipids) were normal and eventually he was started on a hormonal regimen of cyproterone acetate $25 \mathrm{mg}$ twice daily, increasing to $50 \mathrm{mg}$ twice daily after a month and estradiol gel, two pumps daily.

One year later, follow-up hormonal testing revealed suppressed gonadotropins (LH $0.14 \mathrm{IU} / \mathrm{mL}$, FSH $0.11 \mathrm{IU} / \mathrm{mL}$ ) and hyperprolactinemia at $35.97 \mathrm{ng} / \mathrm{mL}$. Estrogen and testosterone were at normal female levels. The hyperprolactinemia was considered secondary to estrogen therapy, as frequently observed in MtF TG patients (a pituitary MRI was negative for prolactinoma). Over the following years, the MtF transition progressed to the patient's satisfaction with a decrease in male-pattern pilosity and an increase in breast size. Biological tests and mammography were performed annually and bone densitometry was done every 2 years. As the patient was satisfied with the results of hormone therapy, no request for gender reassignment surgery was made.

After 7 years of hormone therapy, a routine mammogram revealed retro-areolar micro-calcifications in the right breast, which measured $16 \mathrm{~mm}$ in diameter. The lesion was judged suspicious and micro-biopsies were performed. The histological analysis of the region with micro-calcifications revealed a high-grade ductal in situ carcinoma (DIN 3) without obvious signs of infiltration. The histology of a region without micro-calcifications found an intermediate grade ductal carcinoma in situ (DIN 2) without signs of infiltration. Immunohistochemically, $80 \%$ of cells expressed the estrogen receptor (ER), whereas $10 \%$ expressed the progesterone receptor (PR). HER2 expression was absent. Hormone therapy was stopped immediately after the discovery of the carcinoma. A breast MRI was performed to assess the extent of disease. It revealed multiple foci of enhancement on the right side and a $6 \mathrm{~mm}$ focus of enhancement in the left retro-areolar region. Second-look ultrasound of the left breast revealed an echogenic structure without architectural distortion, or cystic/solid lesions. As the $6 \mathrm{~mm}$ focus of enhancement found on MRI had no corresponding lesion on ultrasound and the patient had stopped hormonal therapy, a follow-up MRI was recommended with complementary biopsy if required. It has remained unchanged to date on long-term follow-up.

A right simple mastectomy with sentinel lymph node biopsy was performed. The histopathology showed focally undifferentiated invasive ductal carcinoma (Fig. 1A), without invasion of sentinel nodes or the nipple. The margins of resection were clear. Analysis of the lesion revealed 100\% ER positivity, $10 \%$ PR positivity, a Ki67 index of 50\%, and negative HER2. Androgen receptor staining showed positivity in $80 \%$ of cells (Fig. 1B). These results represented a formal contraindication to reintroducing hormone therapy. Tamoxifen treatment was recommended, but was declined by the patient. MRI follow-up of the left breast lesion found no progression, therefore the initial MRI focus of enhancement was considered to be the result of prolonged hormone therapy. Follow-up postmastectomy was unremarkable until 30 months after surgery, when local recurrence was diagnosed at the site

Published by Bioscientifica Ltd 

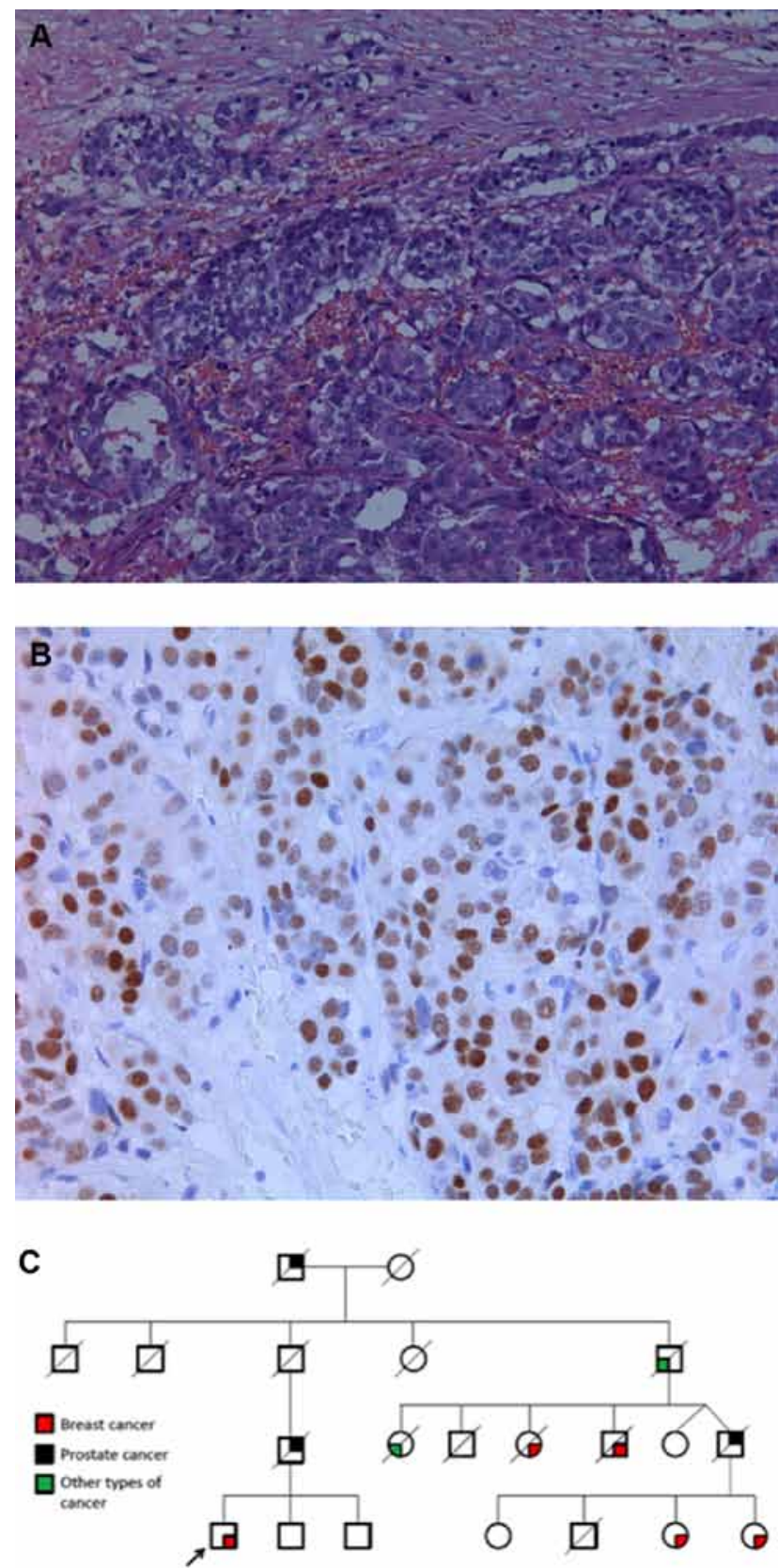

Figure 1

Panel A shows a high magnification (200x) H\&E stain of invasive breast carcinoma resected at mastectomy. In $80 \%$ of the carcinoma cells, androgen-positive receptor was seen (Panel $B ; 400 \times$ magnification). In Panel $C$, the extended family tree of the BRCA2 mutation positive patient is shown with multiple cases of breast and prostate cancers.

of the mastectomy scar. Radiation therapy and adjuvant chemotherapy (epirubicin plus cyclophosphamide, with paclitaxel) were instituted.

Genetic analysis of the BRCA1 and BRCA2 genes was performed and the presence of the heterozygous mutation c. $9117 \mathrm{G}>\mathrm{A}$ in BRCA2 was found. The same mutation had already been noted in a family with the same surname from the same region; however, the patient had made no reference to them previously. Further questioning demonstrated that the patient was indeed related to the family in which the mutation was previously identified (Fig. 1C). Several cases of breast and prostate cancers were present in the kindred, expanding over four generations.

\section{Discussion}

We present the first report of a BRCA2 mutation in a $\mathrm{MtF}$ transsexual patient with breast cancer. The patient was diagnosed with breast cancer at the age of 53, after 7 years of hormonal treatment. A heterozygous c. $9117 \mathrm{G}>\mathrm{A}$ mutation of the BRCA2 gene was found and previously unsuspected links to an extensive kindred with multiple cases of hormone-related tumors were revealed on follow up.

Breast cancer is a rare neoplasm in men. Predisposing factors include genetic predisposition, obesity, estrogentestosterone imbalance (such as those seen in Kleinfelter syndrome) (Brinton et al. 2008). Also potentially implicated are radiation exposure, smoking, and alcohol consumption (Johansen Taber et al. 2010). BRCA2 gene mutations are the main genetic predisposing factor, responsible for around $5-20 \%$ of male breast cancer cases; fewer cases are attributed to BRCA1 mutations (Liede et al. 2004).

MtF TG patients receive hormonal treatment based on their transition needs. Anti-androgens are administered until removal of the gonads, while estrogens are prescribed for longer periods of time, with the dual purpose of promoting feminization and avoiding bone density loss. Often, the doses administered in this setting are higher than those used in the treatment of genetic females for hypogonadism, although the aim is to target normal values of testosterone and estradiol for genetic females. Breast development is a key element in transitioning to a female body form and identity. Historically, various breast augmentation techniques have been attempted, but the current regimens of hormonal treatment often induce the desired changes. Prolonged estrogen treatment combined with anti-androgens lead to the development of lobules and acini and even pseudolactational acinar changes (Kanhai et al. 2000).

Breast cancer occurring in males is typically ductal carcinoma and is more frequently ER and PR positive than in females (Fentiman et al. 2006). Approximately $80 \%$ of male breast cancer patients have a positive status for both

Published by Bioscientifica Ltd 
hormone receptors, as occurred in the current patient (Chavez-Macgregor et al. 2013). In a large breast cancer series in women, BRCA2 mutations were more often found to be ER and PR positive than BRCA1 mutations (Atchley et al. 2008). Triple negative (ER, PR, HER2) cancers were found in $57.1 \%$ of $B R C A 1$ positive cases as compared with only $23.3 \%$ of $B R C A 2$ carriers and $13.8 \%$ of $B R C A$-negative patients (Atchley et al. 2008). In the current case, the prolonged use of high doses of sex steroids (7 years) against the background of a BRCA2 mutation may have contributed to cancer formation.

Recent research has focused on the role of the androgen receptor in breast cancer. In a series of 135 breast cancer patients, androgen receptors were found in $78 \%$ in BRCA2-positive cases compared with $30 \%$ of $B R C A 1$-positive tumors, whereas BRCA-negative tumors expressed AR in $76 \%$ of cases (Pristauz et al. 2010). Androgens were shown to inhibit the proliferation of AR-positive breast cancer cell lines in vitro (Hackenberg et al. 1991). BRCA2 seems to be a coactivator of the AR (Shin \& Verma 2003), which suggests that mutations of the BRCA2 could promote breast tumorigenesis by reducing the antiproliferative effect of androgens. In our patient, AR status was positive in $80 \%$ of cells. Hence, the anti-androgen therapy and BRCA2 mutation positivity could have favored tumorigenesis.

The impact of hormonal treatment on breast cancer risks in MtF patients is controversial. Considering treatment with estrogen, the total lifetime period of exposure is shorter than that for genetic females. However, this could be counterbalanced by the higher doses, different route of administration, and use of more potent compounds. In a large series of transsexual patients treated with cross-sex hormones for a period of 5 to $>30$ years, breast cancer was not more frequent in $2307 \mathrm{MtF}$ patients compared with the expected frequency for genetically male patients (Gooren et al. 2013). Although this is the first report of a BRCA gene mutation in a MtF TG person with breast cancer, to date 12 other cases of breast cancer in MtF TG patients have been reported (Table 1). Most were treated with variable doses and formulations of estrogens for $>10$ years. The most frequent type of cancer in this series was invasive ductal carcinoma, which corresponds to the type most frequently diagnosed in males (Johansen Taber et al. 2010). Among the cases that have reported receptor status, only $50 \%$ were hormone receptor positive, which is less than that usually found in male breast cancer (Johansen Taber et al. 2010). HER2 status was reported in five cases, of which four were found to be negative. In the most recent reports, genetic alterations in the $B R C A$ genes were sought and no anomaly was found. However, older reports mentioned familial cases of breast or unknown types of cancer that could have had a genetic background.

The c.9117G $>$ A BRCA2 mutation seen in this case has already been described in the literature (according to the previous nomenclature, c.9345G>A). Codon 9117 is the last nucleotide in exon 23 and the G-to-A substitution does not alter the amino acid sequence of the protein (p.Pro3039Pro). Although it was previously considered a variant of unknown significance, Acedo et al. (2012) demonstrated that the c. $9117 \mathrm{G}>\mathrm{A}$ change modifies a splice site, resulting in either skipping of exon 23 alone, skipping of exons 23 and 24 or deletion of 51 nucleotides from exon 23. The mutation was inherited from the patient's paternal branch, and several members of the family had prostate and breast cancers. Unfortunately, as the family was large, our patient was unaware of the BRCA2 mutation detected in second-degree cousins.

A thorough family history is important in the evaluation of MtF persons seeking hormonal treatment. As in the current case, the awareness of familial risk by the patients may not be sufficient. As part of the MtF transition process, specific questioning regarding familial occurrence of breast and other cancers could be beneficial. Apart from breast cancer, BRCA2 carriers also have higher risks of developing pancreatic and prostate cancers. Pancreatic cancer in male BRCA2 mutation carriers is 82.5 times more frequent than in the general population (Mersch et al. 2015). The risk of prostate cancer is considered to be five times that of the general population (Mersch et al. 2015), but in male patients under 65 years, it was found to be 7.3 times increased (Breast Cancer Linkage Consortium 1999), whereas in men under 56 years, it was 23 times higher (Edwards et al. 2003). Moreover, prostate cancer in BRCA2 mutation carriers seems to be diagnosed at a younger age and has a more aggressive presentation and a worse prognosis (Tryggvadottir et al. 2007). Other types of cancer may be associated with BRCA2 mutations, such as malignant melanoma and various gastrointestinal neoplasias (Breast Cancer Linkage Consortium 1999, Liede et al. 2004, Mohamad \& Apffelstaedt 2008, Ginsburg et al. 2010), but these associations were not confirmed by other studies and still remain controversial.

A BRCA2 mutation complicates management and follow-up in MtF TG persons. In those who have a BRCA2 mutation diagnosed before initiation of hormonal therapy, cancer risks and alternatives to hormonal therapy (e.g., prosthetic breast augmentation)

Published by Bioscientifica Ltd 
Table 1 Cases of breast cancer in male-to-female transgender patients reported in the literature

\begin{tabular}{|c|c|c|}
\hline Case & Age & Type of breast cancer \\
\hline 1 & 30 & $\begin{array}{l}\text { Poorly differentiated } \\
\text { primary mammary } \\
\text { adenocarcinoma }\end{array}$ \\
\hline
\end{tabular}

2

30 Infiltrating adenocarcinoma, partly scirrhous and partly papillary, unequivocal evidence of its origin as an intraduct carcinoma

345 High-grade infiltrating ductal carcinoma

$450 \quad$ Invasive ductal carcinoma

546 Secretory carcinoma

43 Invasive ductal carcinoma

8 57 Ductal carcinoma

9

46 Initial histology of breast tumor benign; 10 years later generalized poorly differentiated carcinoma with a probable, but unconfirmed breast origin

$10 \quad 55$ Poorly differentiated invasive ductal carcinoma

11 65 Ductal carcinoma in situ

12

60 Infiltrating ductal carcinoma

13
Estrogen treatment and duration

Estrogen orally and implants of estrogen pellets, contraceptive pills for over 6 years and transcutaneous mammary estrogen for an undetermined period

Estrogens orally and subcutaneous pellets for around 5 years, probably estrogen-containing cream applied on breasts for over 2 years

$1.25 \mathrm{mg} /$ day oral conjugated estrogen for 11 years

$0.625 \mathrm{mg} /$ day oral conjugated estrogen for 14 years

Long-term cross-hormone treatment

Estrogen treatment for $>11$ years

Oral conjugated estrogen and cyproterone acetate for 7 years, then intermittent use for 3 years, then estradiol valerate $4 \mathrm{mg} /$ day and cyproterone acetate $50 \mathrm{mg} / \mathrm{day}$ for 5 years Various estrogen preparations for 36 years

Estrogens for 17 years IHC

NR

NR

Genetics Reference

Symmers

(1968)

NR

NR

Symmers

(1968)

$E R-$ (but false

negative possible), PR+

$E R-, P R$ not

reported

ER-, PR-, HER2-

$E R+, P R+$

ER-, PR-, HER2-

Metastatic breast cancer in mother

(Pritchard

et al.

(1988)

NR

Ganly \&

Taylor

(1995)

NR, grandmother died of cancer (unknown)

Grabellus

et al.

(2005)

NR; mother with cancer

Dhand \&

Dhaliwal

(2010)

Negative family history for Pattison \& breast or ovarian cancer

McLaren

(2013)

NR

Gooren

et al.

(2013)

Gooren

et al.

(2013)

Oral conjugated estrogens for unknown period and estradiol valerate $20 \mu \mathrm{g} /$ month for 30 years

\section{Oral conjugated estrogens \\ $E R+, P R+$} $2.5 \mathrm{mg} /$ day for 13 years

Unspecified hormone therapy for 8 years

ER+, PR+, HER2-

$E R+, P R+, H E R 2-$

Estradiol gel 2 pumps/day and cyproterone acetate $100 \mathrm{mg} /$ day for 7 years http://erc.endocrinology-journals.org DOI: 10.1530/ERC-16-0057
(C) 2016 Society for Endocrinology Printed in Great Britain
Published by Bioscientifica Ltd 
should be discussed. Male BRCA2 mutation carriers should undergo surveillance that includes regular self and clinical breast examination, but in men, imaging studies and prophylactic mastectomy are not part of guideline recommendations (National Comprehensive Cancer Network 2016). In BRCA2-positive MtF cases that have hormone-induced breast formation, it would seem prudent to adopt yearly screening mammography and/ or MRI, as would be the case in adult genetic females (Balmaña et al. 2011, National Comprehensive Cancer Network 2016). BRCA2-positive patients have higher risks for prostate cancer. As complications of prostatectomy can be significant, removal of the prostate is generally not part of the sex reassignment surgery of MtF patients (Hembree et al. 2009). Prostate examinations should be performed at least once a year along with prostatespecific antigen measurement. During follow-up, the risk of other potential BRCA2-associated cancers should be kept in mind.

Nearly 1/11,000 males have gender identity dysphoria that leads to MtF transsexualism. The past few decades have seen a better acceptance of transsexualism and increased understanding of the particular healthcare needs of $\mathrm{MtF}$ persons. In parallel, there has been a greater public awareness of the role of genetic mutations of $B R C A$ genes in the risk of endocrine-related cancers. As MtF TG persons attain their desired gender through hormonal treatment, they develop a new physical and personal identity. In parallel they also undergo an important transition in their cancer risks due to hormonal therapy. This case highlights the convergence of two topical endocrine-related issues: MtF TG and BRCA2 mutationrelated cancer risk. It raises an infrequent but crucial aspect in the comprehensive endocrine care of MtF TG individuals.

\section{Declaration of interest}

The authors declare that there is no conflict of interest that could be perceived as prejudicing the impartiality of the research reported.

\section{Funding}

The work was supported in part by a grant from the Fonds de Investissement de la Recherche Scientifique (FIRS) of the University of Liège, Belgium.

\section{References}

Acedo A, Sanz DJ, Duran M, Infante M, Perez-Cabornero L, Miner C \& Velasco EA 2012 Comprehensive splicing functional analysis of DNA variants of the BRCA2 gene by hybrid minigenes. Breast Cancer Research 14 R87.
American Cancer Society 2015 Cancer Facts \& Figures 2015. Atlanta, GA, USA: American Cancer Society.

Atchley DP, Albarracin CT, Lopez A, Valero V, Amos CI, Gonzalez-Angulo AM, Hortobagyi GN \& Arun BK 2008 Clinical and pathologic characteristics of patients with BRCApositive and BRCA-negative breast cancer. Journal of Clinical Oncology 26 4282-4288. (doi:10.1200/JCO.2008.16.6231)

Balmaña J, Díez O, Rubio IT, Cardoso F \& Group Obot EGW 2011 BRCA in breast cancer: ESMO clinical practice guidelines. Annals of Oncology 22 vi31-vi34. (doi:10.1093/annonc/mdr373)

Breast Cancer Linkage Consortium 1999 Cancer risks in BRCA2 mutation carriers. Journal of the National Cancer Institute $\mathbf{9 1}$ 1310-1316.

Brinton LA, Richesson DA, Gierach GL, Lacey JV Jr, Park Y, Hollenbeck AR \& Schatzkin A 2008 Prospective evaluation of risk factors for male breast cancer. Journal of the National Cancer Institute 100 1477-1481. (doi:10.1093/jnci/djn329)

Chavez-Macgregor M, Clarke CA, Lichtensztajn D, Hortobagyi GN \& Giordano SH 2013 Male breast cancer according to tumor subtype and race: a population-based study. Cancer 119 1611-1617. (doi:10.1002/cncr.27905)

De Cuypere G, Van Hemelrijck M, Michel A, Carael B, Heylens G, Rubens R, Hoebeke P \& Monstrey S 2007 Prevalence and demography of transsexualism in Belgium. European Psychiatry 22 137-141. (doi:10.1016/j.eurpsy.2006.10.002)

Dhand A \& Dhaliwal G 2010 Examining patient conceptions: a case of metastatic breast cancer in an African American male to female transgender patient. Journal of General Internal Medicine 25 158-161. (doi:10.1007/s11606-009-1159-6)

Edwards SM, Kote-Jarai Z, Meitz J, Hamoudi R, Hope Q, Osin P, Jackson R, Southgate C, Singh R, Falconer A, et al. 2003 Two percent of men with early-onset prostate cancer harbor germline mutations in the BRCA2 gene. American Journal of Human Genetics 72 1-12. (doi:10.1086/345310)

Evans DG, Susnerwala I, Dawson J, Woodward E, Maher ER \& Lalloo F 2010 Risk of breast cancer in male BRCA2 carriers. Journal of Medical Genetics 47 710-711. (doi:10.1136/ jmg.2009.075176)

Fentiman IS, Fourquet A \& Hortobagyi GN 2006 Male breast cancer. Lancet 367 595-604. (doi:10.1016/S0140-6736(06)68226-3)

Ganly I \& Taylor EW 1995 Breast cancer in a trans-sexual man receiving hormone replacement therapy. British Journal of Surgery 82341

Ginsburg OM, Kim-Sing C, Foulkes WD, Ghadirian P, Lynch HT, Sun P \& Narod SA 2010 BRCA1 and BRCA2 families and the risk of skin cancer. Familial Cancer 9 489-493. (doi:10.1007/ s10689-010-9377-y)

Gooren LJ, Giltay EJ \& Bunck MC 2008 Long-term treatment of transsexuals with cross-sex hormones: extensive personal experience. Journal of Clinical Endocrinology \& Metabolism 93 19-25.

Gooren LJ, van Trotsenburg MA, Giltay EJ \& van Diest PJ 2013 Breast cancer development in transsexual subjects receiving cross-sex hormone treatment. Journal of Sexual Medicine 10 3129-3134. (doi:10.1111/jsm.12319)

Grabellus F, Worm K, Willruth A, Schmitz KJ, Otterbach F, Baba HA, Kimmig R \& Metz KA 2005 ETV6-NTRK3 gene fusion in a secretory carcinoma of the breast of a male-to-female transsexual. Breast 14 71-74.

Hackenberg R, Luttchens S, Hofmann J, Kunzmann R, Holzel F \& Schulz KD 1991 Androgen sensitivity of the new human breast cancer cell line MFM-223. Cancer Research 51 5722-5727.

Hembree WC, Cohen-Kettenis P, Delemarre-van de Waal HA, Gooren LJ, Meyer WJ III, Spack NP, Tangpricha V \& Montori VM 2009 Endocrine treatment of transsexual persons: an endocrine society

Published by Bioscientifica Ltd 
clinical practice guideline. Journal of Clinical Endocrinology \& Metabolism 94 3132-3154. (doi:10.1210/jc.2009-0345)

Hill TD, Khamis HJ, Tyczynski JE \& Berkel HJ 2005 Comparison of male and female breast cancer incidence trends, tumor characteristics, and survival. Annals of Epidemiology 15 773-780. (doi:10.1016/ j.annepidem.2005.01.001)

Johansen Taber KA, Morisy LR, Osbahr AJ III \& Dickinson BD 2010 Male breast cancer: risk factors, diagnosis, and management (review). Oncology Reports 24 1115-1120.

Kanhai RC, Hage JJ, van Diest PJ, Bloemena E \& Mulder JW 2000 Short-term and long-term histologic effects of castration and estrogen treatment on breast tissue of 14 male-to-female transsexuals in comparison with two chemically castrated men. American Journal of Surgical Pathology 24 74-80. (doi:10.1097/00000478-200001000-00009)

Liede A, Karlan BY \& Narod SA 2004 Cancer risks for male carriers of germline mutations in BRCA1 or BRCA2: a review of the literature. Journal of Clinical Oncology 22 735-742. (doi:10.1200/JCO.2004.05.055)

Maglione KD, Margolies L, Jaffer S, Szabo J, Schmidt H, Weltz C \& Sonnenblick EB 2014 Breast cancer in male-to-female transsexuals: use of breast imaging for detection. American Journal of Roentgenology 203 W735-W740. (doi:10.2214/AJR.14.12723)

Mavaddat N, Peock S, Frost D, Ellis S, Platte R, Fineberg E, Evans DG, Izatt L, Eeles RA, Adlard J, et al. 2013 Cancer risks for BRCA1 and BRCA2 mutation carriers: results from prospective analysis of EMBRACE. Journal of the National Cancer Institute $\mathbf{1 0 5}$ 812-822. (doi:10.1093/jnci/djt095)

Mersch J, Jackson MA, Park M, Nebgen D, Peterson SK, Singletary C, Arun BK \& Litton JK 2015 Cancers associated with BRCA1 and BRCA2 mutations other than breast and ovarian. Cancer 121 269-275. (doi:10.1002/cncr.29041)

Miki Y, Swensen J, Shattuck-Eidens D, Futreal PA, Harshman K, Tavtigian S, Liu Q, Cochran C, Bennett LM, Ding W, et al. 1994 A strong candidate for the breast and ovarian cancer susceptibility gene BRCA1. Science 266 66-71. (doi:10.1126/science.7545954)

Mohamad HB \& Apffelstaedt JP 2008 Counseling for male BRCA mutation carriers: a review. Breast 17 441-450. (doi:10.1016/ j.breast.2008.05.001)
National Comprehensive Cancer Network 2016 Genetic/familial highrisk assessment: breast and ovarian. In NCCN Guidelines Version 1.2016 (available at: http://www.nccn.org/professionals/physician_ gls/f_guidelines.asp\#breast).

Pattison ST \& McLaren BR 2013 Triple negative breast cancer in a male-to-female transsexual. Internal Medicine Journal 43 203-205. (doi:10.1111/imj.12047)

Pristauz G, Petru E, Stacher E, Geigl JB, Schwarzbraun T, Tsybrovskyy O, Winter R \& Moinfar F 2010 Androgen receptor expression in breast cancer patients tested for BRCA1 and BRCA2 mutations. Histopathology 57 877-884. (doi:10.1111/j.1365-2559.2010.03724.x)

Pritchard TJ, Pankowsky DA, Crowe JP \& Abdul-Karim FW 1988 Breast cancer in a male-to-female transsexual. A case report. JAMA 259 2278-2280.

Sattari M 2015 Breast cancer in male-to-female transgender patients: a case for caution. Clinical Breast Cancer 15 e67-e69. (doi:10.1016/j.clbc.2014.08.004)

Shin S \& Verma IM 2003 BRCA2 cooperates with histone acetyltransferases in androgen receptor-mediated transcription. PNAS 100 7201-7206. (doi:10.1073/pnas.1132020100)

Thompson D \& Easton D 2001 Variation in cancer risks, by mutation position, in BRCA2 mutation carriers. American Journal of Human Genetics 68 410-419.

Tryggvadottir L, Vidarsdottir L, Thorgeirsson T, Jonasson JG, Olafsdottir EJ, Olafsdottir GH, Rafnar T, Thorlacius S, Jonsson E, Eyfjord JE, et al. 2007 Prostate cancer progression and survival in BRCA2 mutation carriers. Journal of the National Cancer Institute 99 929-935. (doi:10.1093/jnci/djm005)

van Kesteren PJ, Gooren LJ \& Megens JA 1996 An epidemiological and demographic study of transsexuals in The Netherlands. Archives of Sexual Behavior 25 589-600. (doi:10.1007/BF02437841)

Wooster R, Bignell G, Lancaster J, Swift S, Seal S, Mangion J, Collins N, Gregory S, Gumbs C \& Micklem G 1995 Identification of the breast cancer susceptibility gene BRCA2. Nature 378 789-792. (doi:10.1038/378789a0)

Received in final form 16 March 2016

Accepted 21 March 2016

Accepted Preprint published online 21 March 2016 (c) 2016 Society for Endocrinology Printed in Great Britain
Published by Bioscientifica Ltd 